\title{
New Methods for Synthesizing DNA, RNA, and Phosphonates
}

\author{
Marvin H. Caruthers*
}

\begin{abstract}
The development of new methods for the synthesis of DNA, RNA, and phosphonates has enabled new applications in biochemistry and biology.
\end{abstract}

Keywords: DNA synthesis · Phosphonoformate DNA synthesis · RNA synthesis

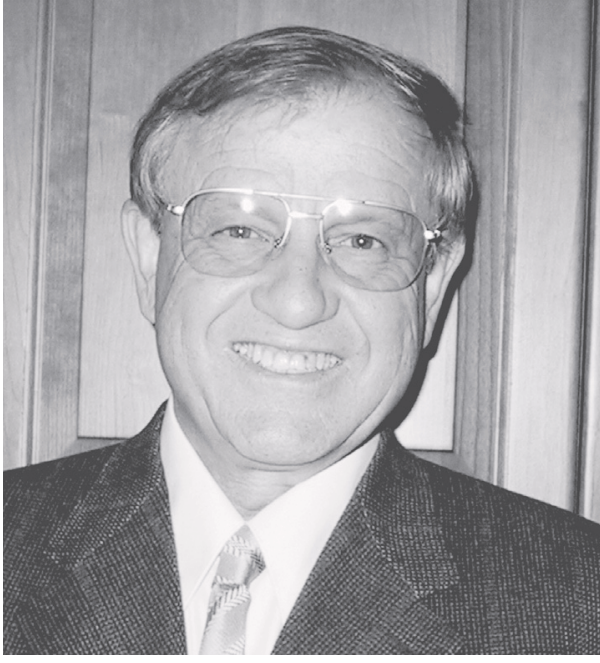

Marvin H. Caruthers

\section{DNA Synthesis}

Over the past twenty years, the method of choice for chemically synthesizing oligodeoxyribonucleotides (ODNs) has been the phosphoramidite four-step process (Scheme 1) [1-3]. Initially, the 5'-dimethoxytrityl (DMT) group is removed from an appropriately protected deoxynucleoside covalently joined to an insoluble support (controlled pore glass or highly crosslinked polysty-
${ }^{*}$ Correspondence: Prof. M.H. Caruthers Department of Chemistry \& Biochemistry University of Colorado

Boulder, CO 80309-0215 USA

Tel.: +13034926095

E-Mail: marvin.caruthers@colorado.edu rene). A repetitive four-step cycle (condensation with tetrazole, acetic anhydride capping of unreactive 5'-hydroxyl groups, iodine oxidation of $\mathrm{P}(\mathrm{III})$ to $\mathrm{P}(\mathrm{V})$, and $3 \%$ trichloroacetic acid detritylation) using deoxynucleoside 3'-phosphoramidites as synthons generates the ODN. The final product is cleaved from the support and obtained free of base and the $\beta$-cyanoethyl phosphate protecting groups by treatment with concentrated ammonium hydroxide. ODNs synthesized with this chemistry continue to be of satisfactory quality for most biological uses such as DNA sequencing, PCR applications, and site-specific mutagenesis.

In recent years, an impetus to develop additional DNA synthesis strategies has emerged due to several new, highly specialized applications. These include DNA microarrays and the use of synthetic DNA for therapeutic purposes and for preparing non-natural genes. The current chemistry, as outlined in Scheme 1, only marginally can be applied to these new applications primarily due to reversibility of the detri- tylation step (which leads to random deletions) and acid catalyzed depurination (lower yields).

In order to overcome these limitations, the chemistry outlined in Scheme 2 has been developed [4]. This procedure not only eliminates problems associated with acid detritylation and depurination but it also provides a two-step synthesis strategy that is both economical and simple (compared to the previous method) which therefore facilitates automation. Generally the approach involves repetitive condensation of appropriately protected 5'-carbonate-2'-deoxynucleoside-3'-phosphoramidite synthons with a 2'-deoxynucleoside joined covalently to a solid support. Each condensation step is followed by treatment with a solution of $m$-chloroperbenzoic acid and hydrogen peroxide buffered at $\mathrm{pH}$ 9.6. This reagent (an $\alpha$-effect nucleophile [5]) oxidizes $\mathrm{P}(\mathrm{III})$ to $\mathrm{P}(\mathrm{V})$ and also removes the carbonate protecting group in an irreversible reaction under conditions that do not modify or degrade ODNs.

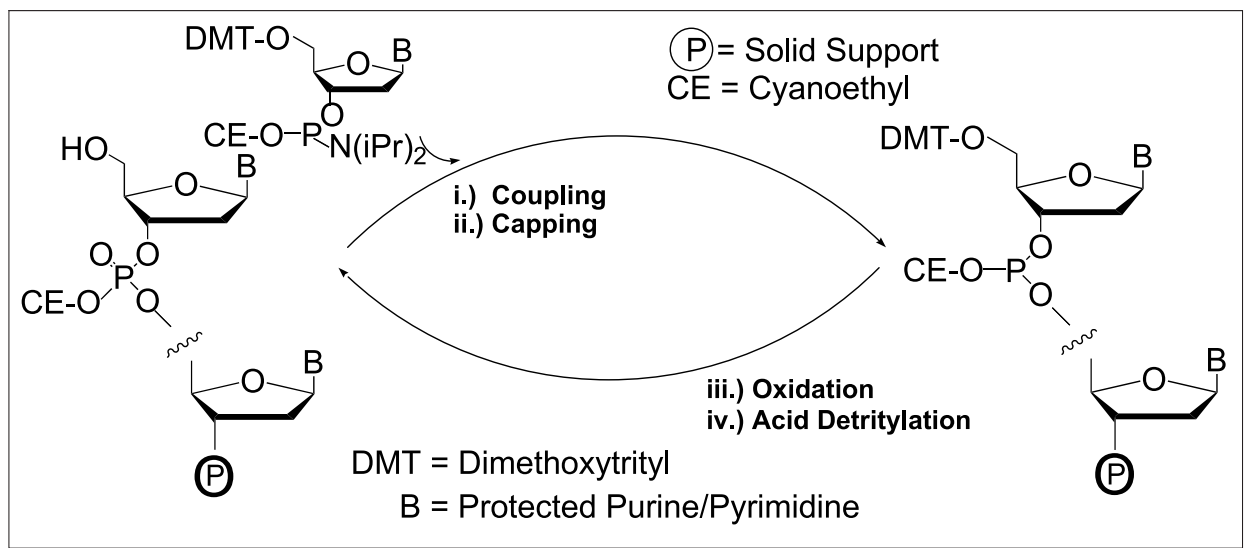

Scheme 1. 


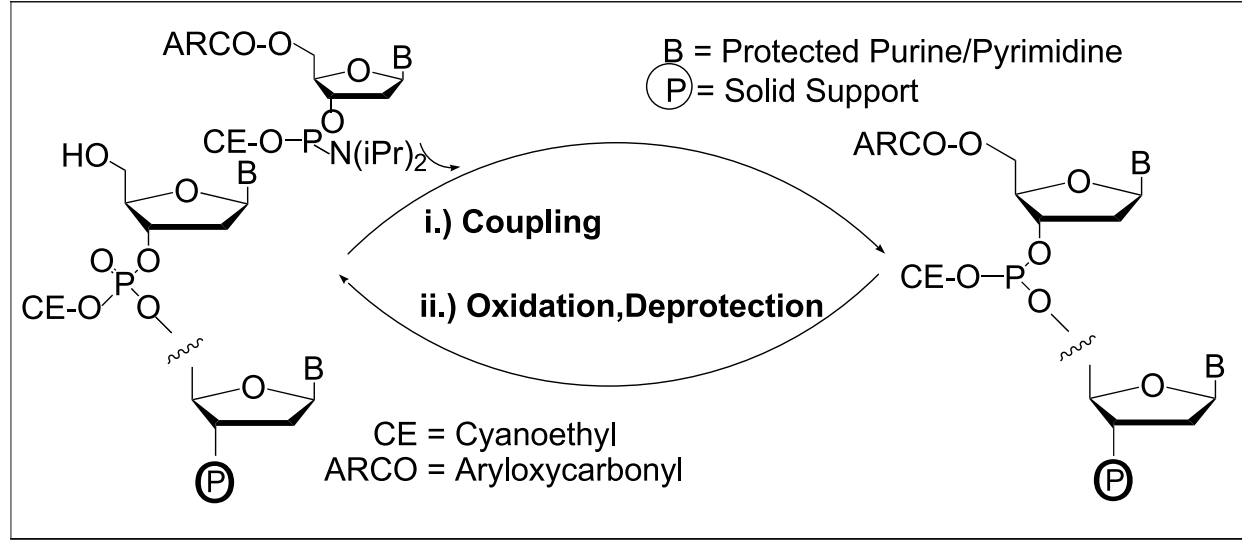

Scheme 2.

Table 1. MALDI-TOF analysis of oligonucleotides

$\begin{array}{lcc}\text { Oligonucleotide } & \text { Calculated } & \text { Molecular weight } \\ \text { d(TIIIITITT) } & 3059.6 & 3057.7(\mathrm{M}-1), 3060.2(\mathrm{M}+1) \\ \text { d(CCCCCCCCCT) } & 2843.5 & 2842.3(\mathrm{M}-1), 2844.5(\mathrm{M}+1) \\ \text { d(AAAAAAAAAT) } & 3059.6 & 3057.7(\mathrm{M}-1), 3060.2(\mathrm{M}+1) \\ \text { d(GTGTGTGTGT) } & 3103.5 & 3101.9(\mathrm{M}-1), 3104.3(\mathrm{M}+1) \\ \text { d(CTCTCTCTCT) } & 2903.5 & 2902.3(\mathrm{M}-1), 2904.4(\mathrm{M}+1) \\ \text { d(ATATATATAT) } & 3023.6 & 3022.7(\mathrm{M}-1), 3024.7(\mathrm{M}+1) \\ \text { d(ATGTCAACTCGTCT) } & 4211.7 & 4210.8(\mathrm{M}-1), 4212.8(\mathrm{M}+1)\end{array}$

The integrity of ODNs synthesized by this two-step procedure has been checked using standard techniques such as ionexchange HPLC and polyacrylamide gel electrophoresis. In order to insure that the purine and pyrimidine bases have not been modified (formation of $\mathrm{N}$-oxides, oxidation of either the 5-methyl of thymidine or the 5,6 double bond of pyrimidines), essentially homopolymers of thymidine, 2'-deoxycytidine, and 2'-deoxyadenosine have been synthesized and analyzed by MALDI-TOF mass spectrometry where oxidation products would have been detected. For 2'-deoxyguanosine, mixed sequences have been prepared as it is difficult to analyze homopolymers of this deoxynucleoside (Table 1). In all cases, for each ODN correct masses confirm the integrity of these oligomers and encourage us to continue to develop this strategy.

\section{RNA Synthesis}

RNA has been found to possess diverse biological functions [6] and structural mo- sion, translation repression, and directing mRNA degradation [11]. An important and indispensable tool for further advancement of research in these fields is the development of methods for the rapid, efficient synthesis of high purity RNA having defined sequences.

The solid-phase chemical synthesis of RNA has lagged behind similar developments with DNA primarily for two reasons: the final RNA product is significantly more susceptible than DNA toward degradation and there is a need for a practical, highly efficient orthogonal protecting group strategy [12]. In order to solve these problems, in addition to several others such as yield and purity, the synthesis strategy outlined in Scheme 3 has been developed in this laboratory. Key elements of the approach, when compared to others [12], are as follows: 1). the use of a fluoride sensitive 5'-silyl group [bis(trimethylsilanoxy)cyclododecanoxysil yl; DOD] and 2). incorporating an acid labile orthoester [bis(2'-acetoxyethoxy)methyl; $\mathrm{ACE}]$ at the 2'-position. By using a thiolate cleavable blocking group on phosphorus (methyl) and base labile protection on the purines and pyrimidines, a completely orthogonal blocking group strategy has been created.

Synthons are added sequentially using $s$-ethyltetrazole as a condensing agent followed by capping with acetic anhydride, oxidation with $t$-butylhydroperoxide, and removal of the silyl group using triethylamine hydrogen fluoride. Yields are in excess of $99 \%$ per cycle. Because fluoride is corrosive to controlled pore glass, insoluble, highly crosslinked polystyrene is used as the synthesis support.

A particularly unique and valuable feature of this synthesis approach is the simple deprotection/purification protocol. The first post-synthesis reaction involves removing the methyl group from phosphorus while the oligomer remains linked to polystyrene. This is carried out with disodium-2-

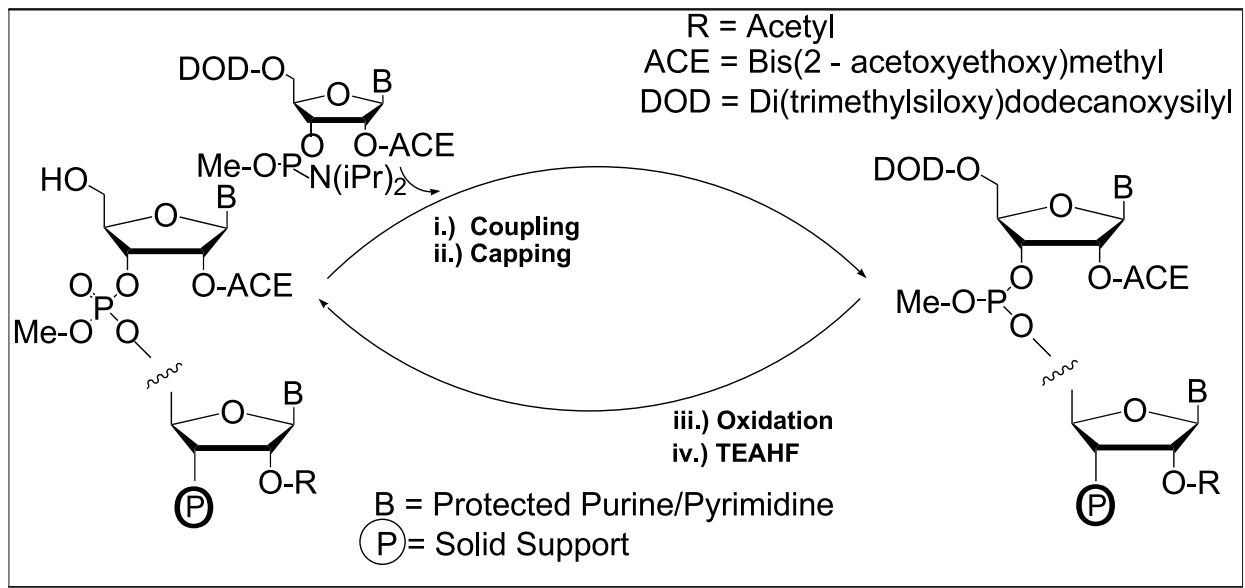

Scheme 3. 
carbamoyl-2-cyanoethylene-1,1-dithiolate. Following an aqueous wash to remove this reagent, the support is treated with a strong base (N-methylamine) which removes exocyclic amine protecting groups, hydrolyzes acetyl from the 2'-ACE (which renders the orthoester approximately ten-fold more labile toward acid) and the 2'-acetyl of the nucleoside joined to the support, and cleaves RNA from polystyrene. The total reaction mixture is then concentrated to dryness in order to eliminate $\mathrm{N}$-methylamine and the 2 -orthoester is removed with $0.1 \mathrm{M}$ acetic acid $\left(30 \mathrm{~min}, 60^{\circ} \mathrm{C}\right.$ ) adjusted to $\mathrm{pH} 3.8$. For most biological applications, oligomers are now ready for use (no column purification). This is because the stepwise yields exceed 99\% and the chemistry generates very few side products. For example, when the total crude reaction mixture from the synthesis of a mixed sequence 21 mer is analyzed by strong ion-exchange HPLC and mass spectrometry (inset) essentially only the expected product is found (Fig. 1).

Based upon these results, RNA oligomers having exceptional purity can now be synthesized rapidly and in high yield. So

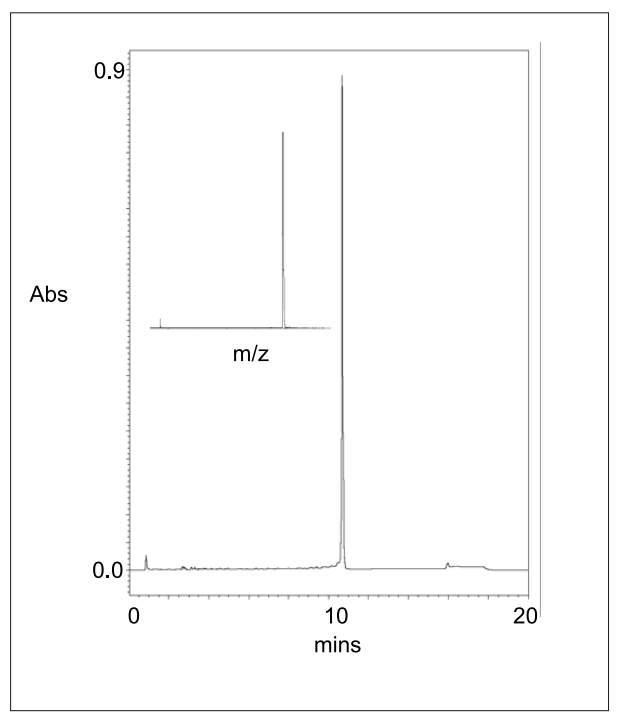

Fig. 1. HPLC and mass spectral analysis of a synthetic oligoribonucleotide 21 mer. The crude reaction mixture following removal of protecting groups was analyzed by strong ion-exchange HPLC. The inset shows the mass spectra analysis of the total reaction mixture. Base composition: $\mathrm{G}_{4} \mathrm{~A}_{9} \mathrm{C}_{2} \mathrm{U}_{6}$. Theoretical mass: 6748. Observed mass: 6749 . far oligomers up to 98 nucleotides have been prepared and used for a diverse group of biological applications [13].

\section{Phosphonoformate DNA}

The search for viable antisense and diagnostic DNA analogs has led to a wide range of candidates [14]. However among these various derivatives, only a limited number possess the properties most commonly identified as necessary for antisense research: activation of RNase $\mathrm{H}$, ability to form sequence-specific duplexes with complementary oligoribonucleotides, and resistance towards nucleases. Even the two analog ODNs that satisfy these criteria, phosphorothioate and phosphorodithioate DNA, have certain undesirable biological properties [15]. Because of these various limitations, this laboratory has continued to focus on developing chemistries leading to the synthesis of new analogs having desirable antisense properties. These include phosphonoacetate DNA [16] and phosphonoformate DNA as outlined in this report.

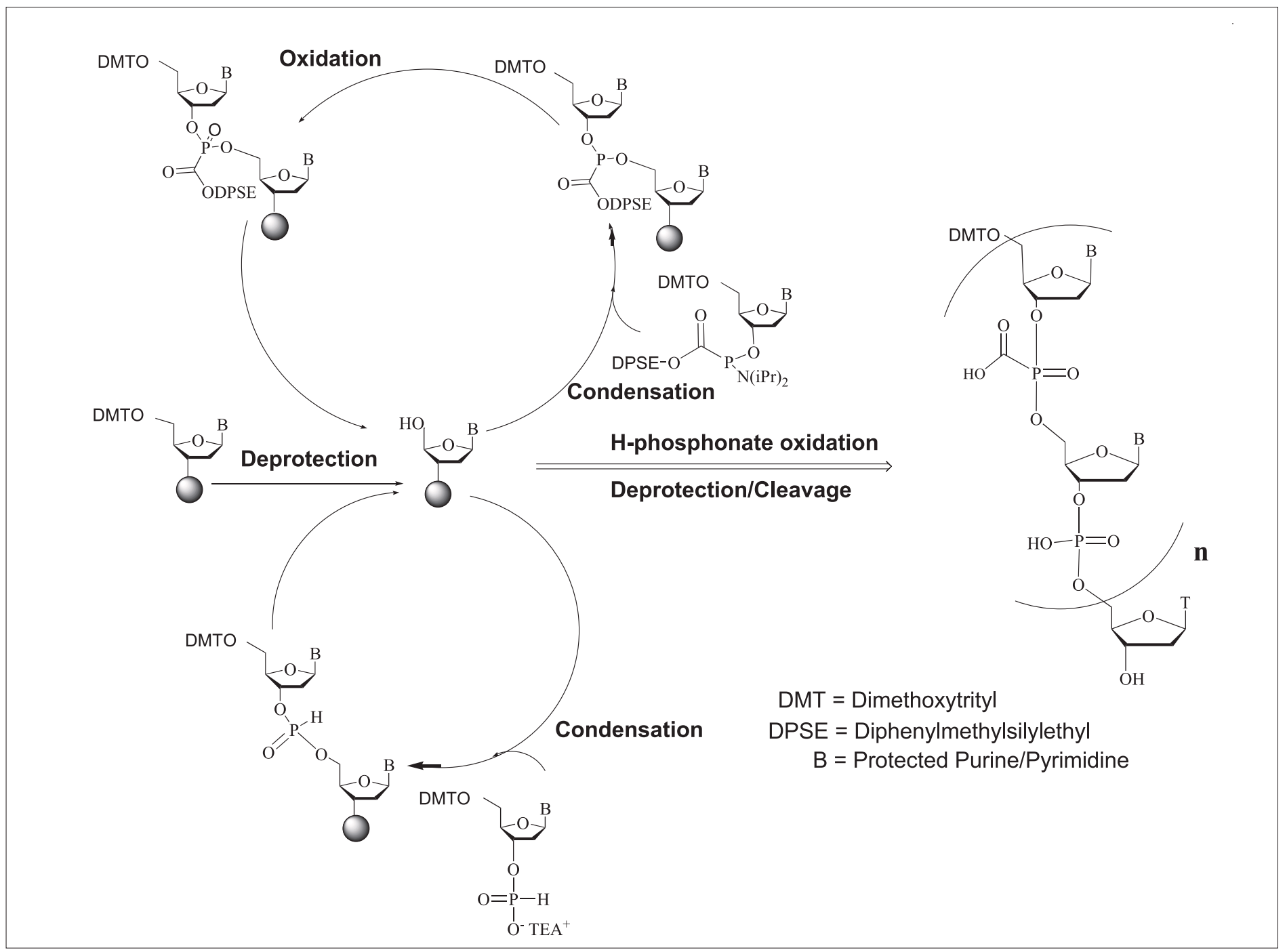

Scheme 4. 
Table 2. Phosphonoformate Cap/Gap sequences: RNase H1 activity

$\begin{array}{lll}\text { Oligo } & \mathrm{k}_{\text {obs }}\left[\mathrm{min}^{-1}\right] & \mathrm{k}_{\text {rel }} \\ \text { dT14 } & 0.766 & 1 \\ \text { dT14 for Gap3 } & 0.118 & 0.15 \\ \text { dT14 for Gap5 } & 0.212 & 0.3 \\ \text { dT14 for Gap7 } & 1.28 & 1.7 \\ \text { dT14 for Gap9 } & 1.42 & 1.9 \\ \text { dT14 for Gap11 } & 1.78 & 2.3 \\ \text { ms2 for Gap11 } & 1.44 & 1.9\end{array}$

Because phosphonoformates are extremely labile to many chemical reagents, almost every major step in the synthesis cycle had to be redesigned (Scheme 4). For example, since the phosphorus-formate linkage is extremely sensitive to nucleophiles, all base labile protecting groups had to be eliminated. Thus the synthons useful for preparing this analog include fluoride labile protection on the formate ester (diphenylmethylsilylethyl, DPSE) and on the exocyclic amino groups of the purine and pyrimidine bases (9-fluorenylmethyloxycarbonyl). Similarly since the standard support linkage is labile only to strong nucleophiles, hydroquinone-O,O'-diacetic acid, which is cleavable with fluoride [17], can be used to join the growing phosphonoformate ODN to highly crosslinked polystyrene. Using this strategy, phosphonoformate ODNs could be prepared with the cycle shown in Scheme 4. However in order to prepare ODNs having mixed backbones (phosphonoformate and phosphate), H-phosphonate synthons are used and oxidized to phosphate. Such a strategy eliminates the need for a phosphate protecting group.

Synthesis of mixed-backbone ODNs having both phosphate and phosphonoformate internucleotide linkages therefore proceeds using appropriately protected 2'-deoxynucleoside 3'-H-phosphonate and 2'-deoxynucleoside-3'-(diisopropylamino) phosphinoformic acid esters (Scheme 4) The condensation reactions are activated with adamantane carbonyl chloride $(\mathrm{H}$ phosphonate) or tetrazole (phosphinoformic acid ester). Stepwise oxidation of the phosphinoformic acid ester is with iodine. Following detritylation with $3 \%$ trichloroacetic acid, synthons can then be interchanged in order to generate any mixed-backbone sequence having all four 2'-deoxynucleosides. Post-synthesis the $\mathrm{H}$-phosphonate linkages are oxidized with iodine and fluoride (TEMED-HF, $\mathrm{pH}$ 8.6) used to remove all protecting groups and to cleave the ODN from the support.

Phosphonoformate ODNs as mixedbackbone oligomers are resistant to nuclease digestion (exonucleases, endonucleases, and HeLa cell extracts), generate A-form duplexes with complementary RNA (measured by circular dichroism) and activate RNase H1. Results demonstrating the latter activity are presented in Table 2. Mixed-backbone ODNs having various internucleotide phosphate linkages (Gap3, Gap5, Gap7, etc. with 3,4,7 phosphates) flanked by phosphonoformate are shown to be active in stimulating RNase $\mathrm{H}$ to degrade complementary RNA (dT14 and mixed sequence, ms, oligomers). When compared to the degradation rate with the natural ODN (dT14), certain oligomers are even more active (relative rates 1.7 to 2.3 times). These results are encouraging and suggest that mixed backbone ODNs having phosphonoformate linkages might be very useful for stimulating RNase $\mathrm{H}$ activity in various biological systems. This would be especially the case if transient ester protection of formate aids in transport of these oligomers across biological membranes (see preliminary research with phosphonoacetate ODNs [18]).

Received: December 9, 2004

[1] R.L. Letsinger, W.B. Lunsford, J. Am. Chem. Soc. 1976, 98, 3655.

[2] S.L. Beaucage, M.H. Caruthers, Tetrahedron Lett. 1981, 22, 1859.

[3] M.D. Matteucci, M.H. Caruthers, J. Am. Chem. Soc. 1981, 103, 3186.

[4] A.B. Sierzchala, D.J. Dellinger, J.R. Betley, T.K. Wyrzykiewicz, C.M. Yamada, M.H. Caruthers, J. Am. Chem. Soc. 2003, $125,13427$.

[5] J.O. Edwards, R.G. Pearson, J. Am. Chem Soc. 1962, 84, 16.

[6] D.D. Draper, Annu. Rev. Biochem. 1995, 64, 593.

[7] P.B. Moore, Аnnu. Rev. Biochem. 1999, 67, 287.

[8] P.B. Moore, T.A. Steitz, Annu. Rev. Biochem. 2003, 72, 813.

[9] D.A. Brow, Annu. Rev. Genetics 2002, 36, 333.

[10] A.R. Ferré-d'Amaré, J.A. Doudna, Annu. Rev. Biophys. Biomolec. Struc. 1999, 28 , 57.

[11] P.A. Sharp, Genes Dev. 2001, 15, 485.

[12] F.E. Wincott, Current Protocols in Nucleic Acid Chemistry (John Wiley and Sons, N. Y.) 2000, Unit 3.5 .

[13] S.A. Scaringe, F.E. Wincott, M.H. Caruthers, J. Am. Chem. Soc. 1998, 120, 11820 .

[14] C.F. Bennett, L.M. Cowsert, Biochim. Biophys. Acta 1999, 1489, 19.

[15] C.A. Stein, Y.C. Cheng, Science 1993, 261, 1004

[16] D.J. Dellinger, D.M. Sheehan, N.K. Christensen, J.G. Lindberg, M.H. Caruthers, J. Am. Chem. Soc. 2003, 125, 940.

[17] R.T. Pon, S. Yu, Nucleic Acids Res. 1997, 25,3629 .

[18] D. Sheehan, B. Lunstad, C. Yamada, B.G. Stell, M.H. Caruthers, Nucleic Acids Res. 2003, 31, 4109. 